\title{
El espectro de William Walker y las discordias en Centroamérica. Constantes en la escritura martiana ${ }^{1}$
}

\section{The Spectrum of William Walker and the Strife in Central America. Constant Threads in Marti's Writing}

\section{O espectro de William Walker e os desentendimentos na América Central. Temas Constantes na Escritura da Marti}

Marlene Vázquez-Pérez

Doctora en Ciencias Literarias

Investigadora titular

Centro de Estudios Martianos

Cuba

Recibido: 4/8/2018

Aceptado: 10/11/2018

DOI: http: //doi.org/10.15359/tdna.35-65.9

\section{Resumen}

En este artículo se valora la importancia que adquieren en la obra de José Martí las referencias a William Walker y a la invasión filibustera en Centroamérica a finales de la década de 1850. Ellas aparecen reiteradamente como imágenes poéticas o en oraciones de claro contenido político en sus crónicas sobre la Conferencia Panamericana. Funcionan como mensajes de alerta respecto a la peligrosa

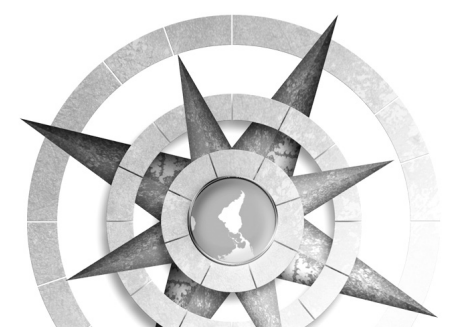

1 Una versión más breve de este artículo fue dictada como conferencia inaugural en el XI Encuentro de Cátedras Martianas, celebrado del 4 al 6 de noviembre de 2013 en la Universidad de Costa Rica, sede del Pacífico. La misma apareció en formato digital en las Memorias de dicho evento. 
They appear repeatedly as poetic images or in sentences of clear political content in his chronicles of the Pan American Conference. They function as warning messages regarding the dangerous neighborship with the United States, which can only be counterbalanced by unity in the region.

Keywords: José Martí, Central America, William Walker, United States.

\section{Resumo}

Este artigo avalia a importância, no trabalho de José Martí, das referências a William Walker e à invasão filibustera dos Estados Unidos na América Central no final da década de 1850. Eles aparecem repetidamente como imagens poéticas ou em frases de conteúdo político claro em suas crônicas da Conferência Pan-Americana. Funcionam como mensagens de aviso sobre a vizinhança perigosa com os Estados Unidos, que só podem ser combatidas pela unidade na região.

Palavras chave: José Martí, América Central, William Walker, United States

\section{Antecedentes}

Para los cubanos, Playa Girón fue la primera gran derrota que sufrió el imperialismo yanqui en América Latina. Si pensamos en la dimensión, repercusión internacional y duración de la batalla, así fue, ciertamente. Sin embargo, repasar la historia de nuestra área geográfica y cultural en el siglo XIX, nos lleva a hacer algunas precisiones. A ello me condujo un encuentro que sostuvimos en el Centro de Estudios Martianos, en mayo del 2013, con los embajadores centroamericanos acreditados en $\mathrm{La}$ Habana. Se habló en aquel momento de la primera rendición yanqui en términos cronológicos: tuvo lugar el 10 de mayo de 1857 , cuando el filibustero William Walker y sus huestes se sometieron a la fuerza combinada de los ejércitos de la región, encabezados por Costa Rica y aliados frente al enemigo común. Sobre Walker, las apetencias imperiales en torno a Centroamérica, las rencillas y alianzas entre hermanos, y la necesidad de superar las diferencias ocasionales en aras del bien de la Patria mayor, estaremos hablando hoy. Todas estas cuestiones fueron constantes significativas en la obra de José Martí. Aunque sus consideraciones fueron formuladas de acuerdo a las circunstancias de su época, por las complejidades del presente merecen atención en este Encuentro de Cátedras Martianas.

Cuando alguien se acerca por primera vez a los Versos sencillos, una de las obras más conocidas y leídas de José Martí, llaman de inmediato su atención unas líneas, procedentes del hermoso prólogo en que el autor cuenta las circunstancias en las cuales fue escrito ese libro. Corría el invierno de 1889, que

116 El espectro de William Walker y las discordias en Centroamérica. Constantes en la escritura martiana 
el cubano vivió como en un pálpito angustioso, debido a que se celebraba la Conferencia Panamericana y al peligro inminente que acechaba a las repúblicas de América. La imagen de los pabellones del Sur en las garras del "águila de Monterrey y de Chapultepec, el águila de López y de Walker" (OC. 2007, t. 14, p. 297) sería una obsesión para él en esos meses: muchas páginas de crónica produjo entonces, dando cuenta del cónclave, pero también escribió sobre el tema en cartas personales y dejó fluir sus dolores patrióticos a través de la poesía.

El lector neófito se preguntará entonces, a tenor de las líneas citadas: ¿Por qué esa asociación de hechos y personajes tan distantes entre sí? Como se sabe, el cubano tenía el hábito de estudiar cada cosa o hecho desde los mismos orígenes, y las entrañas del Congreso, como diría en páginas de aquellos días, estaban, como todas las entrañas, "donde no se las ve"2 Por eso menciona a William Walker en el prólogo, pero también en sus crónicas sobre la conferencia y en otros textos de diferentes épocas. Este aventurero sin escrúpulos

2 Véase la primera crónica sobre el Congreso de Washington, escrita el 28 de septiembre de 1889 , y publicada en La Nación de Buenos Aires, el 8 de noviembre de ese mismo año. Véase OC, t. 6, p. 35. fue, en realidad, un protegido de determinados sectores políticos de su país, sobre todo de los estados del Sur, y no únicamente un filibustero que actuaba por su cuenta.

Pero vayamos en orden cronológico, para no perdernos en la densidad de esa obra copiosa. El hecho inaudito de intentar la conquista de Centroamérica a mediados del siglo XIX, cuando estas repúblicas independientes emprendían caminos propios de desarrollo y habían abolido la esclavitud en sus territorios, grandeza que el vecino del norte no había tenido en su hora de rebelión, demuestra hasta qué punto llegaba el desprecio por los pueblos hispanoamericanos. Para el rubio ambicioso, racista y alentado por la doctrina del Destino Manifiesto, esa región debía ser dominio natural de su bandera. Restaurar la abominable servidumbre y añadir un estado más a los sudistas, con el ánimo de equilibrar el posicionamiento político de estos dentro de su país, eran sus verdaderos objetivos.

La situación de dichos territorios dentro de la Unión era entonces tan tensa, que poco tiempo después estallaría la Guerra de Secesión (1861-1865), único modo de materializar las ideas abolicionistas. En su arrogancia y ambición, el filibustero y sus protectores no contaron con algo: el sentimiento de unidad en la región, a pesar de que no pudo 
sostenerse en la práctica, por encima de desavenencias y discordias entre hermanos, sería capaz, al final, de derrotar al agresor extranjero, como efectivamente ocurrió $^{3}$. Tanto fue así, que luego de la primera invasión y su fracaso, hubo otras dos tentativas infructuosas, sin que el gobierno yanqui hiciera nada por impedirlas, hasta el apresamiento y ejecución de William Walker en Honduras en 1860. Y antes de Centroamérica, el aventurero había intentado, también sin éxito, algo similar en México, al fundar allí, por consiguiente, una "república", de la cual él, por supuesto, sería el "presidente”.

José Martí entendió muy bien el significado de estos hechos, que no eran acontecimientos aislados. Daban continuidad en otro sentido a lo ocurrido durante la Guerra Estados Unidos-México, que concluyó, como sabemos, con la pérdida de cuantiosos territorios y vidas humanas por parte de la nación azteca. Dos

3 No es interés de este examen valorar en todas sus aristas una coyuntura histórica tan compleja y polémica como la Guerra Centroamericana contra los filibusteros. Véase entre otros, el artículo de Víctor Hugo Acuña Ortega "Memorias comparadas: las versiones de la guerra contra los filibusteros en Nicaragua, Costa Rica y Estados Unidos (Siglos XIX - XXI)" en la Revista de Historia (Managua), 2006(20-21).

Disponible en : http://memoriacentroamericana. ihnca.edu.ni/index.php?id=251\&tx_ttnews\%5Btt_news $\% 5 \mathrm{D}=1490 \& \mathrm{cHash}=\mathrm{c} 1 \mathrm{c} 7 \mathrm{ef} 8 \mathrm{bf} 814 \mathrm{ee}$ da310a3d1b19e52881 de las más conocidas batallas de aquella contienda, la de Monterrey y sobretodo la de Chapultepec, ya citadas, se convirtieron en la obra de Martí en motivos recurrentes que aludían de un modo $\mathrm{u}$ otro a la voracidad del peligroso vecino y a su comportamiento antiheroico.

De aquella guerra hablóe $\mathrm{n}$ forma reiterada en diferentes momentos de su vida y obra, pero tal vez la mención más contundente de ella se encuentre en su semblanza antológica "El general Grant”, en especial porque se refería a uno de los estadounidenses más respetados y conocidos de su época, el gran jefe de los ejércitos del norte, vencedor de la Guerra de Secesión.

En este caso, además de ser fiel a la verdad histórica, le servía para alertar a sus lectores del cono Sur respecto a la peligrosa vecindad con Estados Unidos, y a hechos aún cercanos que de manera temporal comprometieron la libertad e integridad del continente. Si tenemos en cuenta que Estados Unidos siempre ha esgrimido pretextos previos a sus agresiones, es de suponer que la información que circulara en la América Hispana por aquel entonces no debió haber sido del todo favorable a la causa mexicana.

La semblanza de Grant que publicara Martí en La Nación, de Buenos Aires, el 27 de septiembre de 1885, contribuiría, indudablemente, a esa labor de preparación, encaminada a garantizar 
el conocimiento mutuo entre nuestros pueblos, indispensable para la soñada unidad continental. Adelantaba así con obras algo que formularía casi como mandato en su ensayo Nuestra América: "Los pueblos que no se conocen han de darse prisa para conocerse, como quienes van a pelear juntos" (OC, t.6, p.15).

En la biografía The Life of Ulysses S. Grant, de Charles A. Dana y James H. Wilson, una de las fuentes que empleara el cubano para la concepción y escritura de esta semblanza, se habla de la participación destacada del joven Grant en el conflicto mexicano-estadounidense. Se describe allí con la minuciosidad de fechas y lugares propia del género cada uno de los combates en los cuales participó, sus principales habilidades como militar y las distinciones de que fue objeto:

Acting in accordance with this chivalrous principle, he took gallant part in the two days' battle of Cerro Gordo, on the 17th and 18th of April. After active operations were resumed, he took part in the capture of San Antonio and the battle of Churubusco, August 20th. At the splendid affair of Molino del Rey, his bravery was so conspicuos that it won for him shortly afterwards the brevet rank of First Lieutenant "for distinguished and meritorious services" [...]. At the storming of Chapultepec, Grant volunteered with a detachment of his company, and assisted in the assault which carried the enemy's entrechments. During the action he took command of a mountain howitzer and served it with such effect as to materially hasten the retreat of the Mexican forces. His conduct upon this occasion attracted the special notice and commendation of his regimental, brigade and division commanders, and following so closely upon his spirited behavior at El Molino el Rey secured for him the brevet of Captain. (Anderson Dana y Harrison Wilson, 1868, p. 63-64) [Actuando de acuerdo a ese principio caballeroso, participó valientemente en los dos días de la batalla de Cerro Gordo, el 17 y 18 de abril. Después de reanudadas las operaciones activas, tomó parte en la captura de San Antonio y en la batalla de Churubusco, el 20 de agosto. En el espléndido hecho de armas de Molino del Rey su valentía fue tan evidente, que le hizo ganar poco después el ascenso a primer teniente, "por servicios distinguidos y meritorios"[...]. En la toma de Chapultepec, Grant se ofreció voluntariamente con un destacamento de su compañía y ayudó en el asalto que condujo a las trincheras del enemigo. Durante la acción tomó el mando de un cañón de montaña con tanto efecto, que aceleró materialmente la retirada de las fuerzas mexicanas. Su conducta atrajo la atención de sus comandantes de regimiento, brigada y división, lo que seguido a su enérgico comportamiento en Molino del Rey le aseguró su ascenso a capitán.] 
Es claro que el fragmento anterior está redactado desde la perspectiva de los vencedores, que en este caso coinciden con los que iniciaron el conflicto e invadieron el territorio vecino bajo el pretexto de disturbios fronterizos y del derramamiento de "sangre americana en suelo americano”, causado por México, según afirmara el presidente Polk. Ello condiciona la simpatía hacia Grant y los suyos, vistos en la bravura que desplegaron en los combates.

Martí, en cambio reordena toda esa información y sin faltar a la verdad desoye el desempeño "heroico" de los que obraron impulsados por intereses mezquinos e invadieron el territorio vecino. Luego de exponer de forma sintética los antecedentes de la conflagración, se detiene a reseñar la participación del militar en la misma:

Taylor marcha sobre México, y lleva a Grant entre los suyos. Adelantan, como suele la injusticia. Grant peleó contra los cadetes imberbes que a la sombra del último pabellón mexicano cayeron sonriendo, apretados uno contra otro, sobre los cerros de lava de Chapultepec (OCEC, t. 22, p. 159).

Como puede verse, obvia los demás combates y solo hace referencia al último. La sola mención de los niños héroes se aleja del tono casi épico del texto fuente, y da la verdadera dimensión de aquella guerra injusta, que con- dujo a México a la pérdida de aproximadamente la mitad de su territorio. La valentía cierta, que Dana y Wilson se complacen en describir, es, según el texto de Martí, - resultado de ese especial proceso de lectura crítica, traducción y reescritura-, escaso mérito para quien tiene de su lado el mayor tesoro: la juventud, que es la fuente de los mejores empeños de cada ser humano. Al inicio del párrafo siguiente reitera lo que ya había referido en las líneas iniciales: el ascenso a capitán obtenido en esta guerra, uno de los hitos fundamentales de esa vida, es un lauro vil por estar fundado en un acto injusto. Con esta referencia, Martí situaba al general y presidente en las antípodas de lo glorioso, y de paso desmitificaba, para los que admiraban desmedidamente al caudillo y al pueblo que lo engendró, el sentido de la libertad imperante en los Estados Unidos: el país de la democracia estaba presto a lesionarla, con cualquier pretexto, más allá de sus fronteras.

En el artículo "Muerte de Grant", publicado una semana antes del retrato mayor en el rotativo bonaerense, concretaba así la vocación expansionista del militar norteño: "Mascaba fronteras cuando mascaba en silencio su tabaco." (OCEC, t. 22, p. 153). De la correspondencia total entre el carácter de este hombre notable y el de su país, fue consciente desde muy temprano. De él había dicho, desde 1884, “[...] Grant es el espíritu norteamericano.- Por donde él va, va

120 El espectro de William Walker y las discordias en Centroamérica. 
su pueblo. Lo concreta: por eso lo guía [...]". (OCEC, 2011, t. 19, p. 25). Luego, en la semblanza, afirmaría: "Culminan las montañas en picos y los pueblos en hombres" (OCEC, t. 22, p. 157). Salvando las distancias inevitables que median entre un presidente y un aventurero, no es exagerado afirmar que ambos pertenecen a una misma genealogía, la de los usurpadores de la libertad ajena en provecho propio, bien sea a favor del país, o de la hacienda personal.

El lance centroamericano de William Walker concretaba una vez más, la larga historia de apetencias estadounidenses e intentos de dominio por vías diversas de las jóvenes naciones situadas al sur del río Bravo. De esa misma estirpe serían las intentonas anexionistas sobre Cuba, encabezadas por Narciso López, también destinadas a la derrota. Detrás del supuesto espíritu emancipador, opuesto al gobierno colonial de la Isla, se escondía la intención de poner a Cuba bajo la égida de un nuevo amo, al que no la unían ni el idioma ni lazos culturales y afectivos de ningún tipo. Casi en los finales del XIX, un hecho que Martí también siguió de cerca, por ser contemporáneo a sus años de estancia en Nueva York fue la maniobra de Augustus K. Cutting contra México en 1886, que por poco desemboca en guerra ${ }^{4}$. Tres

4 Véase al respecto Sarracino, Rodolfo. José Martí y el caso Cutting: ¿Extraterritorialidad o anexionismo? Centro de Estudios Martianos-Universidad de Guadalajara, Guadalajara, 2004. años después, en marzo de 1889, la que pudiéramos llamar, en términos contemporáneos, una de las primeras campañas mediáticas contra América Latina, la difamación contra los cubanos, encubridora de intereses anexionistas, emprendida por el diario filadelfiano The Manufacturer y continuada por el neoyorquino The Evening Post. Ella motivó la respuesta enérgica de Martí, publicada en este último, el 25 de marzo de 1889, la cual ha pasado a la historia como "Vindicación de Cuba."

\section{Centroamérica desde la atalaya neoyorquina}

Cuando el gobierno estadounidense se convenció de la inutilidad de las agresiones directas, unas inconfesadas, como las de Walker, otras francas y abiertas, como la agresión a México, ensayó otros recursos, que encubrían las mismas intenciones. Se trataba de establecer "alianzas panamericanas" para el beneficio único de Washington, como ocurrió cuando el Congreso de 1889 ya aludido. Con el ánimo de conseguir estos propósitos, Estados Unidos hizo todo lo posible para fragmentar el área que Walker invadiera, y también el resto del continente. La política del "divide y vencerás" se convirtió en agenda de trabajo para los altos dignatarios de Washington, y las Escenas norteamericanas de José Martí son pródigas en ejemplos fehacientes. 
El cronista sagaz estuvo siempre al tanto de estas tentativas yanquis, pues percibía que detrás de ellas se escondían planes macabros. Cualquier conflicto interno entre los países del área centroamericana sería siempre aprovechado por la nación que pretendía convertirse en gendarme continental, algo que ha ocurrido también en nuestros días.

Sus llamados a la unidad siempre tuvieron en cuenta esa peculiaridad regional. Por su pequeñez territorial, estas repúblicas necesitaban, tal vez más que el resto del continente, de un bloque unificador que sin restarle la necesaria autonomía a cada una, significara un muro de contención frente a las apetencias foráneas. Una unión que debía estar alentada por la voluntariedad y ajena a las soluciones forzadas y violentas, por bien intencionadas que pudieran ser.

Durante años siguió Martí de cerca el acontecer en la zona, y de ello dio cuenta más de una vez. Alrededor de 1885 subieron de tono las tensiones ante los esfuerzos de Justo Rufino Barrios por imponer su proyecto de unión centroamericana, que no acababa de ser aceptado conforme a sus deseos. Ante la guerra que se desató entonces y la muerte del caudillo guatemalteco, escribió el cubano para sus lectores de La Nación, de Buenos Aires, enterándolos de los acontecimientos, y alertándolos ${ }^{5}$ sobre

5 En estudios anteriores sobre la obra periodística de José Martí nos hemos referido a un modo de la intromisión injustificada de Estados Unidos en el conflicto:

¿A qué vendría la intervención americana, caso de que el Salvador, que ve con malos ojos todo gobierno que le venga de Guatemala, volcase el que ahora tiene, que le ha venido de ella, incapaz de absorber al Salvador por la fuerza, pero capaz aún de gobernarla por medio de un salvadoreño que le prometa no serle hostil en cambio de su alianza?// Sólo estos problemas se abocan en Centroamérica: ¿en qué puede ninguno de ellos afectar a los Estados Unidos, sino en uno que otro ciudadano suyo, que andan allí en número mucho menor que los de cualquiera otra nacionalidad? Pero los pueblos no se forman para ahora, sino para mañana.// Los Estados Unidos se han palpado los hombros y se

expresión que hemos denominado discurso de la alerta, por no encontrar un término afín en la exégesis ya reconocida. Designamos con ello la puesta en escena de un conjunto de recursos expresivos que abarca desde el empleo de determinados signos de puntuación, el uso consciente de vocablos cuidadosamente elegidos para explotar al máximo todas sus posibilidades sémicas, la construcción gramatical de las oraciones, insistiendo, según el caso, en determinado tipo de ellas y no en otros, también factibles, pero no adecuados a la intencionalidad ideológica subyacente; hasta la introducción de imágenes poéticas y formas narrativas y descriptivas que se concretan en el suspenso y la sorpresa para ofrecer, finalmente, la verdad iluminadora. Véase Marlene Vázquez Pérez. La vigilia perpetua. Marti en Nueva York. Centro de Estudios Martianos, La Habana, 2010, pp. 17-18.

122 El espectro de William Walker y las discordias en Centroamérica. Constantes en la escritura martiana 
los han hallado anchos. Por violencia confesada, nada tomarán. Por violencia oculta, acaso. Por lo menos, se acercarán hacia todo aquello que desean. Al istmo lo desean. A México, no lo quieren bien. Se disimulan a sí propios su mala voluntad, y quisieran convencerse de que no se la tienen; pero no lo quieren bien (OC, t. 8, p. 99).

Salta a la vista que no hay interés en censurar. Se vale una vez más de sus altas dotes de escritor para atraer a sus lectores. Es notable en el fragmento citado la efectividad de la sucesión de oraciones interrogativas. Estas mismas opiniones pudieron expresarse en oraciones enunciativas afirmativas, pero no dejarían la misma impronta cognoscitiva e ideológica. La pregunta lleva al lector hacia un proceso autorreflexivo, de debate consigo mismo, que necesariamente lo llevará a responderse la interrogante planteada, y a elaborar conclusiones propias. Más adelante, hemos resaltado el verbo 'andar', que aporta al texto la idea de aventura, de vagar sin rumbo fijo. Ese espíritu de frontera se corresponde enteramente con la naturaleza expansionista y beligerante del país de origen de tales ciudadanos, herederos de William Walker, convencidos de su poderío económico y militar en la región. Lo anterior se expresa en la prosopopeya subrayada, que personifica al país en la figura de ese gigante ególatra y dominador, dispuesto a apoderarse de lo que desee, fiel al precepto de que el fin justifica los medios. Lo anterior tiende a preparar la recepción del cierre de este fragmento: en los riesgos del presente están los desafíos del futuro.

Durante toda la década del 80 estuvo pendiente Martí de las actividades de la Liga de la Anexión Americana, organización en que reencarnaba el espíritu conquistador e irrespetuoso del filibustero. Ella asumía desembozadamente las apetencias encubiertas de muchos prohombres de gobierno, quienes tendían a enmascarar sus verdaderas intenciones. De 1887 es el siguiente párrafo, que merece examen detenido:

Era de noche, como conviene a estas cosas, cuando en los salones de un buen hotel de New York, se reunieron en junta solemne los directores de la "Liga de Anexión Americana" y los delegados de todas las ramas de ella, para hacer un recuento de sus fuerzas y mostrar su poder a los misteriosos representantes que los Estados anexionistas del Canadá envían a la Liga, a la vez que para tributar honores al Presidente de la "Compañía de Ocupación y Desarrollo del Norte de México", al coronel Cutting. Presidía el coronel W. Gibbons, conocido abogado; canadienses había muchos, a más de los delegados de la Liga, cuyo 
objeto inmediato es "aprovecharse de cualquier lucha civil en México, Honduras o Cuba, para obrar con celeridad y congregar su ejército"; pero no había ningún hondureño, ningún cubano, ningún mexicano. "La ocasión puede llegar pronto", decía el Presidente; "lo cierto es que puede llegar de un momento a otro". “¿Honduras también?” preguntó un neófito. "iOh, sí; vea el mapa de Byrne. Honduras tiene muchas minas". "iQue no nos tomen en poco", decía un orador, "que lo que va detrás de nosotros, nosotros lo sabemos; con menos empezó Walker hace treinta años!; sólo que tendremos cuidado con no acabar como él.

Es significativo el modo en que el cubano reordena la información que debe haber obtenido de la prensa de la época, según se infiere de las oraciones entrecomilladas. Crea un ambiente tétrico, en consonancia con los propósitos turbios de sus miembros, declarados, de forma explícita, en esos diálogos dignos de novela naturalista. Obsérvese en la línea enfatizada el anuncio de la futura expansión estadounidense hacia América Latina en los años venideros.

Ya en aquellos momentos había comprendido Martí con creces lo difíciles que se harían las relaciones con el vecino del norte en lo sucesivo. Pruebas sobradas tendría ya al final de esa propia década, cuando fuera contrapartida de los tenebrosos planes de Blaine y sus acólitos durante la Conferencia Panamericana, a los que se enfrentó con todas las armas en su haber, desde la sabiduría política acumulada hasta sus dotes literarias incuestionables.

En aquellos días arduos, Centroamérica fue motivo de preocupación especial para el cubano, pues los conductores de la Conferencia apostaban en nuestros pueblos divididos, una de las armas más eficaces a su favor. En aquel contexto, el poeta, el cronista, el político -que todo eso fue de manera orgánica-, se multiplicó de disímiles maneras para hacer saber a los delegados hispanoamericanos las verdades ocultas tras la estrategia de seducción y presión que diseñara Blaine tan cuidadosamente. $\mathrm{Si}$ no triunfaron entonces los propósitos centrales del cónclave -esto es: la creación de la unión aduanera y la implantación de un sistema de arbitraje obligatorio con sede en Estados Unidos-, se debió en gran medida a la acción inteligente y oportuna del cubano. ${ }^{6}$

6 Sobre la participación de Martí en la Conferencia, ha escrito Rolando González Patricio: "No solo a través de la prensa, como generalmente se cree, sino también directamente a los delegados latinoamericanos a los cuales tuvo acceso, Marti demandó con urgencia poner cuantos frenos fuera posible fraguar con la declaración de la verdad, el pudor de las ideas, el aumento rápido y hábil de los intereses opuestos, y -sobre todo- el ajuste franco y pronto de cuantos tuvieran las mismas razones para temer por la independencia de sus

124 El espectro de William Walker y las discordias en Centroamérica. Constantes en la escritura martiana 
El 19 de diciembre de 1889 pronunció las palabras de bienvenida a los delegados en el homenaje que les ofreciera en Nueva York la Sociedad Literaria Hispanoamericana. Ese discurso, conocido como "Madre América", traza un paralelo histórico entre norte y sur. En él emergen, en una prosa de calidad excepcional, las diferencias existentes entre las dos Américas y sus causas, estudiadas desde los orígenes hasta el presente de Martí. Sobre aquel encuentro memorable con sus compatriotas, las interioridades político-diplomáticas del evento y su intervención de aquella noche, escribió a su amigo mexicano Manuel Mercado cinco días después:

[...] y era mi objeto, porque veo y sé, dejar oír en esta tierra, harta de lisonjas que desprecia, y no merece, una voz que no tiembla ni pide, -y llamar la atención sobre la política de intriga y división que acá se sigue, con daño general de nuestra América, e inmediato del país que después del mío quiero en ella más, -en las tierras confusas y rendidas de Centroamérica. Nadie me lo ve tal vez, ni me lo recompensa; pero tengo gozo en ver que mi vigilancia, tenaz y prudente, no está siendo perdida.

países. Ese fue en síntesis el arsenal político-diplomático fundamental que el cubano empleara contra aquella tentativa de dominio." En: Rolando González Patricio. La diplomacia del Delegado. Editora Política, La Habana, 1998, p. 19
¡Y qué montados, y equivocados, tienen a los guatemaltecos contra México! ¿Qué esfuerzos para hacerles entender que México no es su enemigo, sino en cuanto ellos se presten a ser aliados de los enemigos de México! (Martí, en del Pino y Rodríguez,2003, p. 328-329)7

Contrastar esta carta con una de las crónicas dedicadas a la Conferencia, hace notar al lector -y esto sería ya fuente para otro estudio-, cómo cambia la estrategia comunicativa martiana respecto a asuntos tan delicados. Si en la confidencia privada habla con disgusto de las debilidades internas de nuestra familia de pueblos, en lo escrito para la prensa siempre apostará por elevar la autoestima continental, un modo efectivo de autodefensa frente a las amenazas imperiales. Así, encontramos notables diferencias en su apreciación sobre "las tierras confusas y rendidas de Centroamérica", compartida con su amigo mexicano Manuel Mercado, y su mirada al comportamiento de los territorios hispanoamericanos durante el cónclave, expuesta en uno de sus envíos para La Nación, de Buenos Aires: "[...] la misma Costa Rica, pequeña como una esmeralda, se levanta y dice, después de seis meses provechosos, en que la admiración rudimentaria se ha serenado con el conocimiento real:

7 . [La cursiva es de MVP.] Véase también la carta de Matías Romero a Martí, del 19 de mayo de 1890, en Destinatario José Martí, compilación, ordenación cronológica y notas de Luis García Pascual, La Habana, Casa Editora Abril,1999, pp. 177-178. 
"Pequeño es mi país, pero pequeño como es, hemos hecho más, si bien se mira, que los Estados Unidos" (OC, t. 6, p. 79).

A poco más de un año, el 10 de enero de 1891, publicaba en la Revista Ilustrada de Nueva York, de la cual era propietario Elías de Losada, su cenital ensayo "Nuestra América”. Luego sería reproducido, el 31 del mismo mes, en El Partido Liberal, de México. Siempre me he preguntado cuál sería la idea primigenia del deslumbrante texto martiano, a tenor de su indudable parentesco con el discurso "Madre América". Al rastrear el asunto en el epistolario de esos años, encontramos una carta de Martí a Losada, con fecha del 17 de noviembre de 1890 , de la que se infiere que había recibido una elogiosa misiva del panameño, comentándole alguno de sus escritos, probablemente el discurso "Madre América", y solicitándole colaboración para la revista. Dice allí: "De ningún modo mejor puedo probarle mi agradecimiento por el recuerdo que hace de mí, que aceptando de pleno corazón su encargo de escribir unas cuartillas para el número de enero." (Martí, en García Pascual y Moreno Plá, 1993, t. 2, p. 228).

Una evidencia de que Losada quedó extremadamente complacido y que le escribió a Martí en términos muy laudatorios comentándole sobre su ensayo, es la respuesta del cubano, fechada el 12 de enero de 1891:
Las cosas que $\mathrm{Vd}$. me dice, y que acreditan más su nobleza que mi mérito, no son para que se las responda esta carta, sino mi agradecimiento. iLe diré que he visto con orgullo ese número hermosísimo de La Revista, donde, fuera de lo mío, que está allí tan a la vergüenza pública, todo rebosa arte exquisito y espíritu nuevo? Me pareció el periódico cosa mía, por la tolerancia y pensamiento americano, del bueno, que $\mathrm{Vd}$. pone en él: y tuve el gusto vivo y personal. (1993, pp. 246-247).

Teniendo en cuenta estos precedentes, y la solicitud que le hiciera el intelectual istmeño, ¿cómo no pensar, cuando se leen las mismas líneas iniciales del ensayo, en los pequeños territorios de Centroamérica, enfrentados entre sí y casi inermes ante el poderío del gigante que usa botas de siete leguas? Veamos:

Los pueblos que no se conocen, han de darse prisa para conocerse, como quienes van a pelear juntos. Los que se enseñan los puños, como hermanos celosos, que quieren los dos la misma tierra, o el de casa chica, que le tiene envidia al de casa mejor, han de encajar, de modo que sean una, las dos manos. Los que, al amparo de una tradición criminal, cercenaron, con el sable tinto en la sangre de sus mismas venas, la tierra del hermano vencido, del hermano castigado más allá de sus culpas, 
si no quiere[n] que le[s] llamen el pueblo ladrón, devuélvanle sus tierras al hermano. (OC, t. 6, p. 15)

La unidad tan difícilmente conseguida en momentos cruciales de la historia regional, como aquel 10 de mayo de 1857 , debe ser un ejemplo a seguir en los días que corren.

Estudiar a Martí y a lo más avanzado del pensamiento nuestramericano, es una urgencia del presente. Es por ello que este encuentro, con la pluralidad temática que ha propuesto, se convierte en un espacio propicio para el diálogo, del que se derivarán nuevas inquietudes y perspectivas futuras de trabajo. No quedarnos en el acto placentero y admirado de la lectura que provoca la obra del Maestro, es su mejor homenaje. A Martí hay que leerlo como quería Unamuno, "con devoción inteligente" (Archivo José Martí, Dirección de Cultura, Ministerio de Educación, no. 11, 1947, p. 15). Así le escribía el poeta y pensador español a Joaquín García Monge en 1920, en una carta que al parecer, respondía a la solicitud que le hiciera el editor de Repertorio Americano de su estudio "Notas de Estética. Cartas de poeta" (1947: pp. 16-18).

Repasar ese criterio, emitido en fecha tan temprana de la exégesis martiana, lleva a hacer algunas precisiones. La primera, que ya para entonces se imponía con creces la dimensión universal del pensador cubano. Observar que un hombre de la estatura intelectual del rector salmantino le hubiese dedicado comentarios de ese nivel de certidumbre, y que un centroamericano reclamara para su emblemática revista, de alcance y declarados propósitos ecuménicos, un texto dedicado al epistolario de Martí, habla en bien de la trascendencia de su obra, reconocida por el pensamiento avanzado y los cultores de la lengua española.

Convertir todo el caudal de pensamiento aquí reunido en acción fecunda y transformadora; crear y conocernos mejor, son las urgencias actuales: a la altura del siglo XXI, ya es una certeza que, con trincheras de ideas o con trincheras de piedras, o con las dos, a despecho de invasiones foráneas y discordias internas, seguro vamos a pelear juntos.

\section{Referencias bibliográficas}

Anderson Dana, Ch. y Harrison Wilson, J. (1868). The Life of Ulysses Simpson Grant, General of the Armies of the United States. Springfield, Mass. Gurdon Bill \& Company.

de Unamuno, M. (1947, enero-diciembre). Carta a Joaquin García Monge. [Carta] Dirección de Cultura, Ministerio de Educación, Archivo José Martí, no 11, La Habana. 
. (1947, enero-diciembre). "Notas de Estética. Cartas de poeta." [Carta] Dirección de Cultura del Ministerio de Educación, Archivo José Martí, no. 11, La Habana: Dirección de Cultura del Ministerio de Educación

del Pino, M. y Rodríguez, P. comp., (2003). José Martí: Correspondencia a Manuel Mercado. Introducción de Cintio Vitier. La Habana: Centro de Estudios Martianos.

García Pascual, L. y Moreno Pla, E. comp., (1993). José Martí. Epistolario, Tomo II, La Habana: Centro de Estudios Martianos y Editorial de Ciencias Sociales

Martí, J. (2001). "La Conferencia de Washington", en Obras Completas, t. 6, p. 79, La Habana: Centro de Estudios Martianos. . (2007). Obras completas. Edición crítica. Tomo 14. La Habana: Centro de Estudios Martianos.

. (2007). Obras Completas Edición Crítica. Tomo 22. La Habana: Centro de Estudios Martianos.
. (2011). "Exhibición de arte en Nueva York para el pedestal de la Estatua de la Libertad." La América, Nueva York, enero de 1884, en Obras Completas Edición Crítica. Tomo 19. La Habana: Centro de Estudios Martianos. . (2011). "El Congreso de Washington", en Obras Completas. Tomo 6. La Habana: Centro de Estudios Martianos (2011). Obras Completas. Tomo 7. La Habana: Centro de Estudios Martianos. (2011). Obras Completas. Tomo 8. La Habana: Centro de Estudios Martianos.

Vázquez Pérez, M. (2010). La vigilia perpetua. Martí en Nueva York. La Habana: Centro de Estudios Martianos. 